\title{
Short Communication: Association Analysis of Microsatellites and Mycobacterium avium Subspecies paratuberculosis Antibody Response in German Holsteins
}

\author{
M. Hinger, ${ }^{*}$ H. Brandt, ${ }^{*}$ S. Horner, $\dagger$ and G. Erhardt ${ }^{\star 1}$ \\ *Justus-Liebig University, Department of Animal Breeding and Genetics, Giessen, Germany \\ †Animal Health Service of Thuringia, Bad Langensalza, Germany
}

\begin{abstract}
Paratuberculosis in ruminants is characterized by chronic granulomatous enteritis, resulting in persistent diarrhea and progressive wasting of cattle infected with Mycobacterium avium ssp. paratuberculosis (MAP). The disease occurs worldwide with high frequency, leading to growing economic losses in beef and dairy industries. The objective of this study was to investigate associations of microsatellites (BMC9006, BB704, $B B 705, B B 717, B B 719, B M S 1617, B B 702$, and $B O B T 24)$ located near or within candidate genes involved in response mechanisms to paratuberculosis. Pedigree information existed for 4,686 German Holstein cows that had routinely been screened for MAP status using commercially available serum antibody ELISA test. The immunoglobulin G cutoff level was used to classify all animals as positive or negative for paratuberculosis. A total of $594(12.7 \%)$ cows tested positive for paratuberculosis. The control group comprised 585 animals testing negative for MAP. Microsatellite BMC9006 had only 3 alleles ( 2 of which occurred at very low frequencies in the present data set) and was therefore not informative; the remaining microsatellites showed 3 to 12 alleles. Fisher's exact and $\chi^{2}$ tests revealed no significant differences in microsatellite allele frequencies between the 2 groups of German Holstein cows testing positive or negative for paratuberculosis.
\end{abstract}

Key words: paratuberculosis, microsatellite, susceptibility, German Holstein

Paratuberculosis in ruminants is caused by Mycobacterium avium ssp. paratuberculosis (MAP). Clinical disease is characterized by a chronic granulomatous enteritis, persistent or intermittent diarrhea, and excessive loss of weight. Worldwide economical losses due to MAP

Received November 23, 2006.

Accepted November 28, 2006.

${ }^{1}$ Corresponding author: Georg.Erhardt@agrar.uni-giessen.de result from the long incubation period, reduced performance in production traits, and lack of effective therapy (reviewed by Chacon et al., 2004). Mycobacterium avium ssp. paratuberculosis is potentially a crucial factor in the development of Crohn's disease in humans (Greenstein, 2003; Grant, 2005).

Breeding strategies to enhance resistance of cattle against mycobacterial infections could be an additional method to hygienic programs in combating paratuberculosis. The estimated heritability of paratuberculosis in different goat breeds ranges from 0.01 to 0.15 (Singh et al., 1990). Heritability based on microbiological and histological postmortem examination of slaughtered cows was assessed by Koets et al. (2000). They estimated a heritability of 0.06 for the overall population of vaccinated and nonvaccinated cattle. A Danish study tested milk samples of 11,535 Danish dairy cows using ELISA. When based on a multivariate model, the data showed a heritability of 0.10 for the humoral antibody response. Applying a univariate model with whole pedigrees, a heritability of 0.10 was attained. Implementing a sire model showed a heritability of 0.09 . A low and nonsignificant correlation $(-0.037)$ was also found between antibody level and daily milk yield (Mortensen et al., 2004). Gonda et al. (2006a) studied daughters of 12 sires previously tested for paratuberculosis infection by using both ELISA and fecal culture. The combined test resulted in an estimated heritability of 0.10 . Gonda et al. (2006b) also identified a QTL for paratuberculosis susceptibility on Bos taurus autosome 20 in US Holsteins.

All preceding studies confirm genetic influence on paratuberculosis susceptibility despite low heritability estimates.

Genetic resistance is the inherent capacity of a previously unexposed animal to resist disease when challenged by pathogens (Adams and Templeton, 1998). Although there is no particular gene known to be responsible for differences in paratuberculosis susceptibility in cattle, SLC11A1 (formerly natural resistance associated macrophage protein $1, N R A M P 1$ ) is associ- 
ated with natural resistance to infection with Salmonella spp., Leishmania spp., and Mycobacterium spp. in the mouse (Vidal et al., 1993). Genetic variants of SLC11A1 in humans are partly responsible for resistance against tuberculosis (Bellamy, 2000) and have been associated with resistance against Brucella abortus infection in cattle (Adams and Templeton, 1998; Barthel et al., 2001), but do not determine resistance or susceptibility to bovine tuberculosis (Barthel et al., 2000). Reddacliff et al. (2005) discovered a possible association of one SLC11A1 microsatellite allele with severe clinical paratuberculosis in sheep. Furthermore, IL-12 is a crucial cytokine in control of mycobacterial infections. Mutations in the IL12 gene and its receptor lead to increased susceptibility to mycobacterial infections (reviewed by Basu, 2004). Tumor necrosis factor$\alpha$ response to mycobacterial antigens is weaker in the blood of MAP-infected cattle compared with uninfected ones, which may have negative effects on granuloma formation and function (Buza et al., 2003). Expression of the IL10 gene was increased in tissues of clinically diseased cows compared with healthy controls and subclinically infected animals (Khalifeh and Stabel, 2004). Finally, just as IFN- $\gamma$ is a major cytokine involved in macrophage activation and resistance to mycobacteria (Stabel, 1996), IL-18 is an important regulator of innate and acquired immune responses (Akira, 2000). The aim of this study was to analyze possible associations of microsatellites located near or within these candidate genes with susceptibility to MAP in cattle.

Eight microsatellites were chosen for this purpose due to their close linkage to the above mentioned candidate genes involved in immune response against mycobacteria (Table 1).

Pedigree information existed for 4,686 German Holstein cows originating from 13 German farms. All of these animals had routinely been screened for MAP status within a surveillance program in Thuringia in spring 2005. Herd sizes varied from 53 to 784 animals. The occurrence of animals testing positive ranged between 2.8 and $36.8 \%$ within farms. Complete lactation data were available for 4,590 of these cows. To describe the lactation yield of all tested animals, the mean and standard deviations for milk production traits are presented in Table 2 (records with DIM below $250 \mathrm{~d}$ were excluded). Antibody levels were determined by using commercially available ELISA tests (IDEXX test, IDEXX, Wörrstadt, Germany; Svanovir, Svanova, Uppsala, Sweden) and results were recorded as optical density (OD) percentage values or sample-to-positive (S/ P) values for each cow, respectively. The test-specific IgG antibody cutoff level (IDEXX: $\mathrm{S} / \mathrm{P}$ value $=0.25$; Svanovir: OD $=53 \%$ ) was used to classify all animals as positive or negative for paratuberculosis, which re- sulted in a total of 594 (12.7\%) positive cows. The control group comprised 585 animals testing negative for MAP, each of which correlated in age at the time of testing, was descended from the same sire, and originated from the same farm as at least 1 of the positive animals. Regarding both groups, the animals descended from 246 sires with an average number of 4.8 progeny. If no matching half-sib was present in the population, older animals born on the same farm and with repeated negative test results were chosen as controls. The average age of the negative control group was slightly higher (51.3 mo) than the age of the positive animals ( 48.7 mo), which was expected because of choosing older animals as controls in cases of no matching half-sibs available.

The DNA was extracted from whole blood samples using Invisorb Blood Mini HTS 96-Kit/C-Sheep (Invitek $\mathrm{GmbH}$, Berlin, Germany) and stored at $4^{\circ} \mathrm{C}$ before use. Details on microsatellites used in this study are shown in Table 1. In each case, a fluorescent dye [FAM (6carboxyfluorescein), VIC, or NED] was attached to the $5^{\prime}$ end of the reverse PCR primer. As nontemplated addition of a nucleotide to the $3^{\prime}$ end of the PCR-amplified product of BB704 and BMC9006 occurred, the sequence GTTTCTT was added to the $5^{\prime}$ end of the reverse primer to facilitate accurate genotyping (Brownstein et al., 1996). Microsatellite loci were coamplified using the ABsoluteQPCR Mix (ABgene Germany, Hamburg, Germany) in 2 groups: $B B 704, B B 705, B B 717, B B 719$, and $B M C 9006$ (multiplex 1) and $B M S 1617, B B 702$, and $B O B T 24$ (multiplex 2). One nontemplate negative control and a reference sample were amplified in every PCR reaction to standardize the results. Reactions were carried out in a total volume of $15.0 \mu \mathrm{L}$, containing $50 \mathrm{ng}$ of target DNA, $1 \times$ ABsoluteQPCR Mix (ABgene Germany), and $1 \times$ primer mix. Final concentration for each primer pair varied between 0.5 and $1.25 \mathrm{pmol} / \mu \mathrm{L}$. The PCR reactions were performed in 96 -well microtiter plates using an iCycler temperature cycler (Bio-Rad, München, Germany) programmed for 15.0-min denaturation at $95^{\circ} \mathrm{C}$, followed by 30 cycles of 0.5 -min denaturation at $94^{\circ} \mathrm{C}, 1.5$-min annealing at $62^{\circ} \mathrm{C}$ (multiplex 2 ) or $63^{\circ} \mathrm{C}$ (multiplex 1), and 1.0-min extension at $72^{\circ} \mathrm{C}$, followed by a final extension period of $30.0 \mathrm{~min}$ at $60^{\circ} \mathrm{C}$. Fragment analysis was performed using the ABI Prism 377 DNA Sequencer and Genotyper (V 3.7 NT) Gene Scan Analysis software (both from Applied Biosystems, Darmstadt, Germany).

For each microsatellite, allele frequencies between MAP-positive animalss and the control group were compared using the $\chi^{2}$ and Fisher's exact tests. Allele frequencies below $5 \%$ were grouped together for this statistical test (see Table 3). Besides BMC9006, the microsatellites BB704, BB705, BB717, BB719, BMS1617, 
Table 1. Primer sequences (underlined = PIGtail) of forward $(f)$ and reverse ( $r$ ) primers, fluorescent labels (FAM, VIC, NED), and range of allele size of microsatellites

\begin{tabular}{|c|c|c|c|c|}
\hline Microsatellite & Locus & $\begin{array}{l}\text { Bos taurus } \\
\text { autosome }\end{array}$ & Primer sequences $\left(5^{\prime} \rightarrow 3^{\prime}\right)$ & $\begin{array}{l}\text { Allele size } \\
\quad(b p)\end{array}$ \\
\hline BB704 ${ }^{1}$ & IL12A & 1 & $\begin{array}{l}\text { GTTTCTTTTAAGCAGGGACGAACGTG (f) } \\
\text { NED-AATTGCCAGGAAGATTGTGG (r) }\end{array}$ & $107-145$ \\
\hline $\mathrm{BMC} 9006^{2}$ & SLC11A1 & 2 & $\begin{array}{l}\text { GTTTCTTGTGGAATGAGTGGGCACAG (f) } \\
\text { FAM-CCTTCCAGAACTCCCTCTCC }(\mathrm{r})\end{array}$ & $223-231$ \\
\hline $\mathrm{BMS} 1617^{3}$ & IFN- $\gamma$ & 5 & $\begin{array}{l}\text { GCCTGCATGTGTCTGTGG }(\mathrm{f}) \\
\text { FAM-TCTGTGTCGGAATACCCTCC (r) }\end{array}$ & $143-165$ \\
\hline BOBT $24^{4}$ & IL4 & 7 & $\begin{array}{l}\text { GAGCAAGGGAATTCAGTGGAGC (f) } \\
\text { NED-TGTATTTTACATTCAGGTCTGTGATCC (r) }\end{array}$ & $146-165$ \\
\hline $\mathrm{BB} 719^{1}$ & IL12B & 7 & $\begin{array}{l}\text { AAATGCCAGGACCTCACAG (f) } \\
\text { VIC-GCTAGGAGATGTTGCTGCTG (r) }\end{array}$ & $254-284$ \\
\hline $\mathrm{BB} 702^{1}$ & IL18 & 15 & $\begin{array}{l}\text { TAGCCACTGGACCATCAGG }(\mathrm{f}) \\
\text { VIC-TGGCATTAGACCATGACAGC (r) }\end{array}$ & $186-198$ \\
\hline $\mathrm{BB} 717^{1}$ & IL10 & 16 & $\begin{array}{l}\text { TGAGTCACCTGCAAGTTTGA (f) } \\
\text { VIC-GTCTGGTCCCAGTTTTGCA (r) }\end{array}$ & $152-164$ \\
\hline $\mathrm{BB} 705^{1}$ & TNF- $\alpha$ & 23 & $\begin{array}{l}\text { GGGAGGTCTTTCCTACAGTGC (f) } \\
\text { FAM-CACAAAGAGTCAGACACAGTTTAGC (r) }\end{array}$ & $118-128$ \\
\hline
\end{tabular}

\footnotetext{
${ }^{1}$ Sonstegard et al. (2000).

${ }^{2}$ Feng et al. (1996).

${ }^{3}$ Stone et al. (1995).

${ }^{4}$ Buitkamp et al. (1996).
}

BB702, and BOBT24 showed 3 to 12 alleles. Both applied tests revealed no significant differences in microsatellite allele frequencies between the 2 groups of Holstein cows testing positive or negative for paratuberculosis. Microsatellite BMC9006 showed only 3 alleles, 2 of which displayed very low frequencies in the present data set. This finding is in accordance with that of Paixao et al. (2006), who investigated 81 Bos taurus (Holstein) cattle and 167 animals from Bos indicus breeds with regard to brucellosis resistance and detected $100 \%$ of Holsteins homozygous for one allele, (GT)13. A survey of B. indicus (Hariana) and B. indicus $\times$ B. taurus crossbred cattle for the (GT)13 repeat in the $3^{\prime}$ untranslated region of SLC11A1 also revealed only homozygotes (Kumar et al., 2005). Our results are based on ELISA tests (specificities: IDEXX $=94 \%$; Svanovir $=76 \%$ ), which could lead to inappropriate classification of MAP-negative (control) animals. The main problem for genetic studies regarding paratuberculosis is the definition of infection and disease status, resulting in difficult acquisition of material (Reddacliff et al., 2005). Paratuberculosis infection can be divided into 3 stages, noninfected, infected with predominating cellmediated immune response (and therefore low humoral antibody response), and infected with predominating humoral antibody response and elevated antibody titers (Nielsen et al., 2002a). Some infected cows never progress to a clinical state accompanied by typical symptoms and no test can indicate whether an infected animal will later develop clinical paratuberculosis. The sensitivity of diagnostic tests for paratuberculosis is low and depends on the stage of disease (Nielsen et al., 2002b). The existence of breed-specific differences in susceptibility to infectious diseases in cattle has not been adequately addressed (Barthel et al., 2000). Additional diagnostic measures such as fecal culture and expanded sampling may give further insight into the contribution

Table 2. Raw means and standard deviations of all animals, the Mycobacterium avium ssp. paratuberculosis (MAP)-positive group, and the control group for milk production traits per lactation ${ }^{1}$

\begin{tabular}{|c|c|c|c|c|c|c|}
\hline \multirow{2}{*}{$\begin{array}{l}\text { Milk production } \\
\text { trait }\end{array}$} & \multicolumn{2}{|c|}{$\begin{array}{l}\text { All animals } \\
(\mathrm{n}=4,590)\end{array}$} & \multicolumn{2}{|c|}{$\begin{array}{l}\text { MAP-positive group } \\
\quad(\mathrm{n}=580)\end{array}$} & \multicolumn{2}{|c|}{$\begin{array}{l}\text { Control group } \\
(\mathrm{n}=574)\end{array}$} \\
\hline & Mean & SD & Mean & SD & Mean & SD \\
\hline Yield (kg) & 8,338 & 1,784 & 8,281 & 1,599 & 8,455 & 1,791 \\
\hline Fat $(\mathrm{kg})$ & 335.3 & 69.2 & 325.2 & 61.7 & 335.1 & 69.0 \\
\hline Protein (kg) & 281.4 & 55.2 & 278.5 & 49.9 & 283.8 & 56.1 \\
\hline
\end{tabular}

${ }^{1}$ Only lactations with more than 250 DIM were included. 
Table 3. Number of animals genotyped (n) and allele frequencies (\%) of microsatellites BB704, BMC9006, BMS1617, BOBT24, BB719, BB702, BB717, and BB705 of Mycobacterium avium ssp. paratuberculosis (MAP)-positive animals (positive), control group (negative), and results of $\chi^{2}$ test and Fisher's exact test

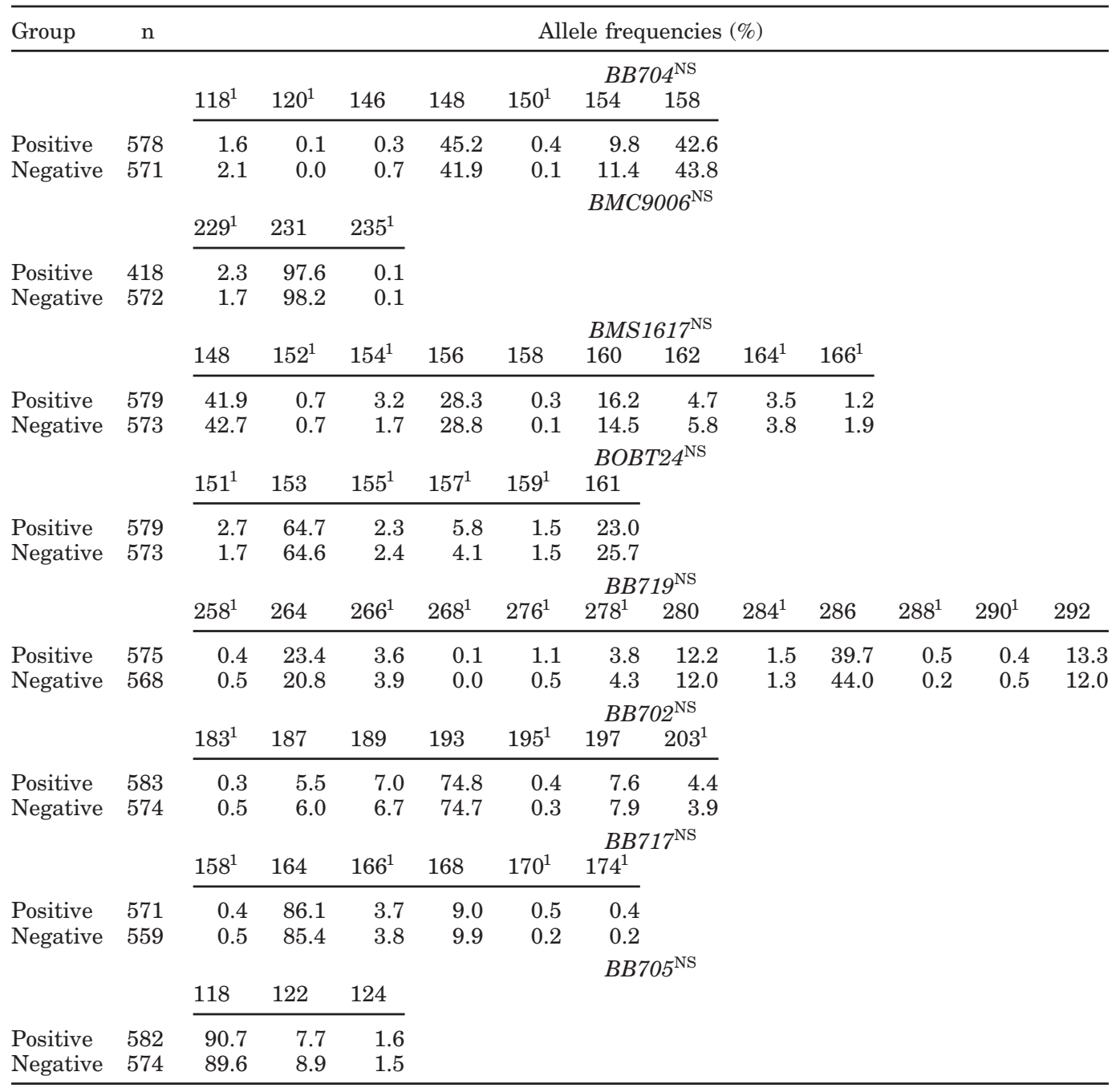

${ }^{1}$ Rare alleles with frequencies below $5 \%$ in the total sample were combined for statistical evaluation.

NS $=$ not significant.

of the investigated microsatellites to paratuberculosis susceptibility in German Holstein cattle.

\section{ACKNOWLEDGMENTS}

The authors would like to thank Vereinigte Informationssysteme Tierzucht (Verden, Germany) for providing official lactation records, S. Wack for excellent technical assistance, and the Hessian Ministry for Science and Art for financing this study as part of the project "Mensch-Ernährung-Umwelt."

\section{REFERENCES}

Adams, L. G., and J. W. Templeton. 1998. Genetic resistance to bacterial diseases of animals. Rev. Sci. Tech. 17:200-219.
Akira, S. 2000. The role of IL-18 in innate immunity. Curr. Opin. Immunol. 12:59-63.

Barthel, R., J. Feng, J. A. Piedrahita, D. N. McMurray, J. W. Templeton, and L. G. Adams. 2001. Stable transfection of the bovine NRAMP1 gene into murine RAW264.7 cells: Effect on Brucella abortus survival. Infect. Immun. 69:3110-3119.

Barthel, R., J. A. Piedrahita, D. N. McMurray, J. Payeur, D. Baca, F. Suarez Guemes, V. S. Perumaalla, T. A. Ficht, J. W. Templeton, and L. G. Adams. 2000. Pathologic findings and association of Mycobacterium bovis infection with the bovine NRAMP1 gene in cattle from herds with naturally occurring tuberculosis. Am. J. Vet. Res. 61:1140-1144.

Basu, J. 2004. Mycobacteria within its intracellular niche. Survival of the pathogen or its host? Curr. Sci. 86:103-110.

Bellamy, R. 2000. Identifying genetic susceptibility factors for tuberculosis in Africans: A combined approach using a candidate gene study and a genome-wide screen. Clin. Sci. 98:245-250.

Brownstein, M. J., J. D. Carpten, and J. R. Smith. 1996. Modulation of non-templated nucleotide addition by Taq DNA polymerase: Primer modifications that facilitate genotyping. Biotechniques 20:1004-1010. 
Buitkamp, J., G. Obexer-Ruff, M. Kessler, and J. T. Epplen. 1996. A microsatellite (BOBT24) located between the bovine IL4 and IL13 loci is polymorphic in cattle and goat. Anim. Genet. 27:212-213.

Buza, J. J., Y. Mori, A. M. Bari, H. Hikono, G. Aodon, S. Hirayama, Y. Shu, and E. Momotani. 2003. Mycobacterium avium subsp. paratuberculosis infection causes suppression of RANTES, monocyte chemoattractant protein 1 , and tumor necrosis factor alpha expression in peripheral blood of experimentally infected cattle. Infect. Immun. 71:7223-7227.

Chacon, O., L. E. Bermudez, and R. G. Barletta. 2004. Johne's disease, inflammatory bowel disease, and Mycobacterium paratuberculosis. Annu. Rev. Microbiol. 58:329-363.

Feng, J., Y. Li, M. Hashad, E. Schurr, P. Gros, L. G. Adams, and J. W. Templeton. 1996. Bovine natural resistance associated macrophage protein 1 (Nramp1) gene. Genome Res. 6:956-964

Gonda, M. G., Y. M. Chang, G. E. Shook, M. T. Collins, and B. W. Kirkpatrick. 2006a. Genetic variation of Mycobacterium avium ssp. paratuberculosis infection in US Holsteins. J. Dairy Sci. 89:1804-1812.

Gonda, M. G., G. E. Shook, B. W. Kirkpatrick, and M. T. Collins. 2006b. Quantitative trait locus affecting susceptibility to Mycobacterium paratuberculosis infection identified on BTA 20 in US Holsteins. Proc. 30th Intern. Conf. Anim. Genet., Porto Seguro, Brazil. Int. Soc. Anim. Genet., Porto Seguro, Brazil.

Grant, I. R. 2005. Zoonotic potential of Mycobacterium avium ssp. paratuberculosis: The current position. J. Appl. Microbiol. 98:1282-1293.

Greenstein, R. J. 2003. Is Crohn's disease caused by a mycobacterium? Comparisons with leprosy, tuberculosis, and Johne's disease. Lancet Infect. Dis. 3:507-514.

Khalifeh, M. S., and J. R. Stabel. 2004. Upregulation of transforming growth factor-beta and interleukin-10 in cows with clinical Johne's disease. Vet. Immunol. Immunopathol. 99:39-46.

Koets, A. P., G. Adugna, L. L. Janss, H. J. van Weering, C. H. Kalis, G. H. Wentink, V. P. Rutten, and Y. H. Schukken. 2000. Genetic variation of susceptibility to Mycobacterium avium subsp. paratuberculosis infection in dairy cattle. J. Dairy Sci. 83:2702-2708.

Kumar, N., A. Mitra, I. Ganguly, R. Singh, S. M. Deb, S. K. Srivastava, and A. Sharma. 2005. Lack of association of brucellosis resistance with (GT)(13) microsatellite allele at 3' UTR of NRAMP1 gene in Indian zebu (Bos indicus) and crossbred (Bos indicus $\times$ Bos taurus) cattle. Vet. Microbiol. 111:139-143.

Mortensen, H., S. S. Nielsen, and P. Berg. 2004. Genetic variation and heritability of the antibody response to Mycobacterium avium subspecies paratuberculosis in Danish Holstein cows. J. Dairy Sci. 87:2108-2113.

Nielsen, S. S., Y. T. Grohn, and C. Enevoldsen. 2002a. Variation of the milk antibody response to paratuberculosis in naturally infected dairy cows. J. Dairy Sci. 85:2795-2802.

Nielsen, S. S., C. Gronbaek, J. F. Agger, and H. Houe. 2002b. Maximum-likelihood estimation of sensitivity and specificity of ELISAs and faecal culture for diagnosis of paratuberculosis. Prev. Vet. Med. 53:191-204.

Paixao, T. A., C. Ferreira, A. M. Borges, D. A. Oliveira, A. P. Lage, and R. L. Santos. 2006. Frequency of bovine Nramp1 (Slc11a1) alleles in Holstein and Zebu breeds. Vet. Immunol. Immunopathol. 109:37-42.

Reddacliff, L. A., K. Beh, H. McGregor, and R. J. Whittington. 2005. A preliminary study of possible genetic influences on the susceptibility of sheep to Johne's disease. Aust. Vet. J. 83:435-441.

Singh, N., S. N. Kala, V. S. Vihan, and V. S. Singh. 1990. Genetic study on susceptibility to Johne's disease in goats. Indian J. Anim. Sci. 60:1163-1165.

Sonstegard, T. S., W. M. Garrett, G. L. Bennett, S. M. Kappes, D. S. Zarlenga, and L. C. Gasbarre. 2000. Mapping of seven bovine cytokine genes involved in T-lymphocyte growth, differentiation and immune response. Anim. Genet. 31:406-408.

Stabel, J. R. 1996. Production of gamma-interferon by peripheral blood mononuclear cells: An important diagnostic tool for detection of subclinical paratuberculosis. J. Vet. Diagn. Invest. 8:345-350.

Stone, R. T., J. C. Pulido, G. M. Duyk, S. M. Kappes, J. W. Keele, and C. W. Beattie. 1995. A small-insert bovine genomic library highly enriched for microsatellite repeat sequences. Mamm. Genome 6:714-724

Vidal, S. M., D. Malo, K. Vogan, E. Skamene, and P. Gros. 1993. Natural resistance to infection with intracellular parasites: Isolation of a candidate for Bcg. Cell 73:469-485. 